\title{
IoT in Smart Cities' Utility Systems: from prototype to production
}

\author{
Daniil Bolobonov \\ Graduate School of Business and \\ Management \\ Peter the Great St.Petersburg \\ Polytechnic University \\ Saint Petersburg, Russia \\ daniil.bolobonov@mail.ru \\ Alexander Frolov \\ Graduate School of Business and \\ Management \\ Peter the Great St.Petersburg \\ Polytechnic University \\ Saint Petersburg, Russia \\ a.k.frolov@ya.ru
}

\author{
Igor Ilin \\ Graduate School of Business and \\ Management \\ Peter the Great St.Petersburg \\ Polytechnic University \\ Saint Petersburg, Russia \\ ivi2475@gmail.com
}

\author{
Igor Korolev \\ Graduate School of Business and \\ Management \\ Peter the Great St.Petersburg \\ Polytechnic University \\ Saint Petersburg, Russia \\ ia-korolev@yandex.ru
}

\begin{abstract}
Smart Cities, Industrial Internet of Things (IIoT), Smart Grids and etc. are products of Industry 4.0 that are on verge on becoming mass-implemented after ${ }^{1}$ years in development by different companies and startups. While these technologies are nowhere from being completely novel, they have significant undiscovered potential. Companies invest millions into research and development and often fail to achieve desired outcome due to blurred vision, prolonged development and other reasons. This paper analyzes errors during system modeling cycle while also proposing framework for developing IIoT system in Smart City that enables companies to accelerate development of new products while also reducing costs. IIoT system developed by the authors of this paper is an end-to-end solution for Smart Cities that mainly focuses on gathering data of housing sector's utility systems such as water pressure and temperature, voltage and others. During development several working prototypes had to be scrapped due to not meeting requirements of potential and real customers. Over time an approach that allowed rapid incorporation of customer requests into the solution was developed. It includes modular hardware coupled with microservice-based cloud software and agile software development. Application of this approach allowed to satisfy needs of increasing number of customers.
\end{abstract}

Keywords-Industrial Internet of Things, Smart City, IIoT system, Digital transformation

\section{INTRODUCTION}

Continuous cost reduction of smart industrial devices (sensors and gateways) and increase in computing power and capacity are the key factors that drive digital transformation. Nowadays organizations face the pressure more than ever to transform their businesses in order to stay competitive and meet new market, regulatory and consumer demands. $[1,2$, 3]

Utilities industry is considered to be one of the early adopters of the concept due to clear understanding of how
IoT technologies can drive costs saving and achieve regulatory compliance. [4,5] The study by Statista [6] positions utilities industry among the leaders in spending on IoT related technologies, solutions and platforms, as depicted in Fig. 1.

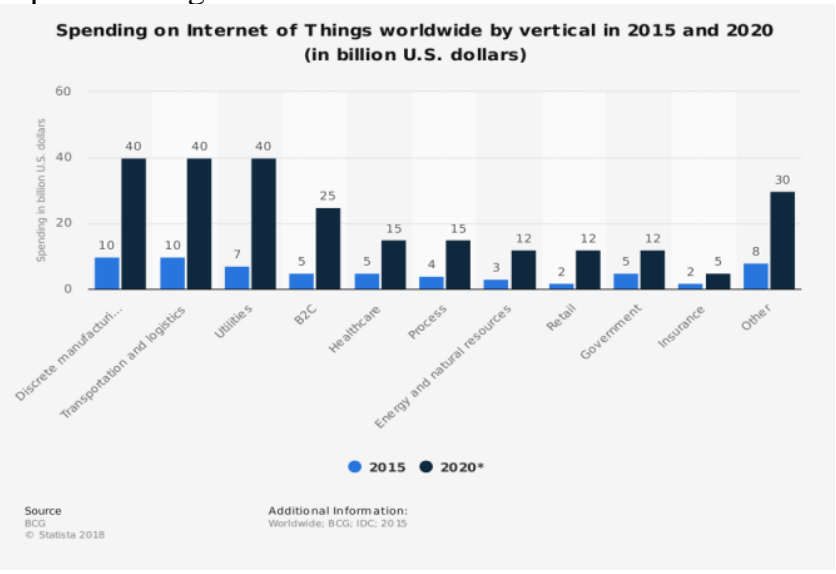

Fig. 1. Worldwide spending on IoT across top industries (estimated value in 2015 and projected value in 2020)

As could be derived from Fig. 1, by 2020, organizations from utilities industry (along with discrete manufacturing and transportation and logistics) are projected to spend $\$ 40 \mathrm{~B}$ on IoT platforms, systems, and services. According to [7] the companies from utilities industry are generally investing in IoT technology to transform their operations and enhance customer experience.

One may argue that the data is more representative when considering adoption of IoT in a given industry from the standpoint of implemented projects. Fig. 2 presents the results of the research conducted by IoT Analytics in 2018. [8] 


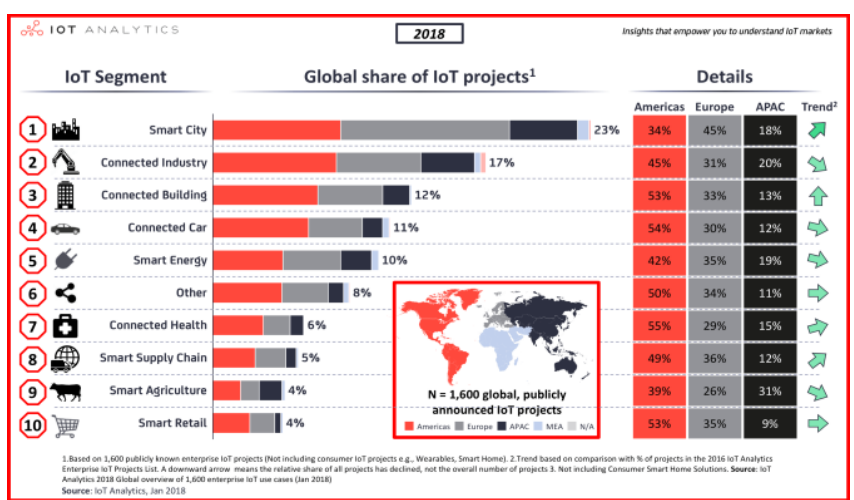

Fig. 2. Global share of IoT projects across top segments

Today, there is a number of implemented innovative IIoT scenarios in utilities industry. The term "innovative IIoT scenario" refers to a possible use case where the concept and technologies of Internet of Things could be applied to achieve certain business goals of an organization operating in a certain industry. The most common IoT use case in utilities industry is automatic meter reading (AMR) via smart meters. [9] Some organizations operating in utilities industry are offering their customers simple applications for managing and tracking consumption rates of a given resource. For instance, smart water management enables consumers to receive automated notice of leaks, which otherwise may go undetected until the following month' $\mathrm{s}$ bill arrives. From the system operators' stand point, such solutions provide possibility to collect data automatically, without need to visit the physical meter in the field. The rapid evolution of such solutions has been caused by legal regulation as well as commercial requirements. $[10,11,12]$

In a significant number of countries legal regulations demand organizations operating in utilities industry to provide accurate meter data readings at defined time intervals to all suppliers for billing purposes. [13,14] Automation of this process enables metering system operators to collect data of a higher quality and do so much faster, using less manpower than manual reading. Successful implementation of AMR solution helps organizations to transform their processes to be more cost-efficient by enabling accurate collection of data based on actual consumption from possibly millions of meters. Obviously, when smart meters are estimated to be in millions AMR solution ought to provide the functionality to operate and upgrade every node remotely.

Another key functionality of AMR is providing near realtime information on resource consumption and transmission. This data enables organizations to set up more efficient, demand-based resource generation and distribution processes. For instance, utility companies can additionally influence demand by offering consumers the choice to use a resource only at the times specified by them. For the endclient, such transparent pricing results in lowering of their bills and, therefore, helps to build trustworthy relations with an organization. This, for its part, provides organizations operating in utilities industry an opportunity to promote value-adding services to the client, for instant, solutions for smart house and so on. Summarizing all mentioned above, leveraging IIoT concept to its full potential of enables utilities companies to build deeper consumer relationships and new revenue streams over time. [15]

\section{PRODUCT DEVELOPMENT}

Over the course of two years startup by D. Bolobonov and A. Frolov developed five hardware prototypes and three different IT services, accorsing to the service-oriented architecture concept, actively developed in Peter the Great Saint Petersburg Polytechnic University [16,17]. Each was an evolutionary development of the previous one. Initially, device that was being developed had to gather pressure from three water pipes and temperature from two of them. At that time developers also proposed to include leakage, movement and fire sensors. Startup used well-known ESP8266 development board with Arduino framework. As the device should have been connected to the IT service using GPRS modem and ESP8266 only have Wi-Fi and Bluetooth on board, external modem was purchased. Fig. 3 presents architecture of the first prototype. SAP Cloud Platform for Internet of Things was used as IT service. It was decided that GPRS modem should be integrated into device and Arduino Nano was selected as development board. Later it was discovered that Arduino sketches use too much of scarce internal storage of Nano and all proposed functionalities could not been implemented.

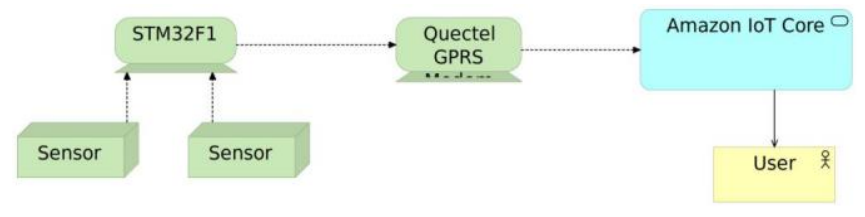

Fig. 3. Initial architecture

Development team needed more control over hardware and software, so they began to research available technologies. Most promising hardware line was STM32 microcontrollers with rich and professional documentation while also popular among DIY hobbyists and SIM modems most popular ones. This line of devices had professional integrated development environment, graphical code generator and debuggers. Developers only knew $\mathrm{C}++$ language but it was decided that $\mathrm{C}$ will be used to speed up development cycle due to generated code being written in $\mathrm{C}$. Developers had to take $\mathrm{C}$ and STM32 course, leading to halt in development. At the same time, market research for IoT solutions was prepared. It showed that Amazon services satisfied all customer' $\mathrm{s}$ requirements and were much cheaper than analogs. Second team started to develop solution which had Amazon IoT Core as IoT gateway and custom JavaScript as front-end. Architecture of that solution is presented on Fig. 4.

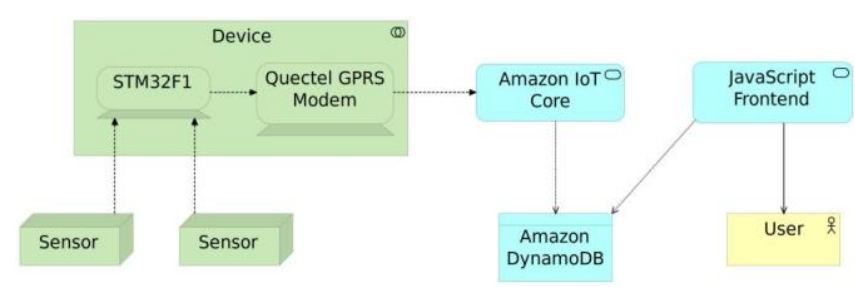

Fig. 4. Modified architecture

Over time, it was acknowledged that SIM GPRS module was obsolete and did not support encryption standards 
enforced by Amazon. Modem was changed for model by Quectel.

Amazon infrastructure was convenient, however, its services could not be modified to meet needs of the team and and also were frequently unavailable due to blocking by Roscomnadzor. To overcome this issue another market research was completed and ThingsBoard solution was selected as a base for new service. It also had microservice architecture as Amazon solution while also being highly customizable. At the same time, number of startup' s client have risen and their requirements for the hardware could not be met in time. The solution to this problem was modular architecture of the device which is presented on Fig. 5.

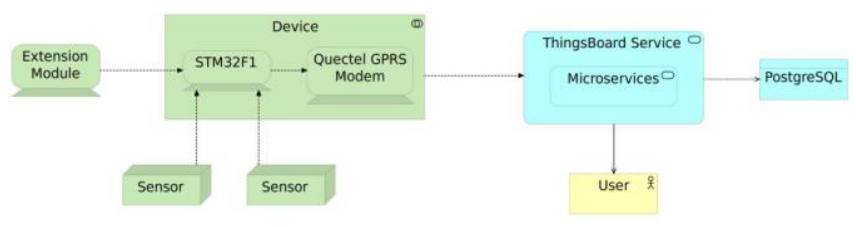

Fig. 5. Current architecture

At the current time the research for using Digital Twin for entire lifecycle of the product is being conducted.

\section{DEVELOPMENT APPROACH}

Here we present the approach that helped us to deliver updates to the customers faster and to make less mistakes while doing so.

1) Everything have to be documented in some form. Product requirements have to have business objectives, background, assumptions, user stories, questions and things out of scope.

2) Every member have to be familiar with agile approach. All development process have to be written down in project management system with project requirements in mind.

3) Every part of the technology used in the project have to be extensively reviewed and validated as being compatible with other technologies.

4) Before major development cycle a strategy must be produced - strategic map may be used to explore new technologies and skills that developers need to study.

5) Solutions need to be modular and highly customizable to increase development speed.

\section{ACKNOWLEDGMENT}

The reported study was funded by RSCF according to the research project № 19-18-00452

\section{REFERENCES}

[1] Borremans A.D., Zaychenko I.M., Iliashenko, O.Yu. (2018). Digita economy. IT strategy of the company development. MATEC Web of Conferences Volume 170, 13 June 2018. International Science Conference on Business Technologies for Sustainable Urban Development, SPbWOSCE 2017. Paper number 010342017

[2] Zaychenko I.M., Ilin I.V., Lyovina A.I. (2018). Enterprise Architecture as a Means of Digital Transformation of Mining
Enterprises in the Arctic. In: Proceedings of the 31st International Business Information Management Association Conference (IBIMA). Pp.4652-4659

[3] Ilin, I., Levina, A., Abran, A., Iliashenko, O. (2017). Measurement of enterprise architecture (EA) from an IT perspective: Research gaps and measurement avenues. Paper presented at the ACM International Conference Proceeding Series, Part F131936, 232-243.

[4] Simmhan, Y., Ravindra, P., Chaturvedi, S., Hegde, M., \& Ballamajalu, R. (2018). Towards a data-driven IoT software architecture for smart city utilities. Software: Practice and Experience, 48(7), 1390-1416

[5] Levina, A.I., Dubgorn, A.S., Iliashenko, O.Y. Internet of things within the service architecture of intelligent transport systems (2018) Proceedings - 2017 European Conference on Electrical Engineering and Computer Science, EECS 2017, pp. 351-355.

[6] Statista.: Spending on Internet of Things worldwide by vertical in 2015 and 2020. https://www.statista.com/statistics/666864/iotspending-by-vertical-worldwide/ (2017). Accessed 23 Apr 2019

[7] Rémi Bonnefoi, Christophe Moy, Jacques Palicot. (2017) Framework for hierarchical and distributed smart grid management. General Assembly and Scientific Symposium of the International Union of Radio Science (URSI GASS)

[8] Scully, P.: The Top 10 IoT Segments in 2018 - based on 1,600 real IoT projects. IoT Analytics. https://iot-analytics.com/top-10-iotsegments-2018-real-iot-projects/ (2018). Accessed 25 Apr 2019

[9] Lloret, J., Tomas, J., Canovas, A., \& Parra, L. (2016). An Integrated IoT Architecture for Smart Metering. IEEE Communications Magazine, 54(12), 50-57

[10] Sánchez L., Elicegui I., Cuesta J., Muñoz L., Lanza J. (2013). Integration of Utilities Infrastructures in a Future Internet Enabled Smart City Framework. Sensors 2013; 13(11), 14438-14465

[11] Lepekhin A.A., Borremans A.D., Iliashenko, O.Yu. Design and implementation of IT services as part of the "Smart City" concept. MATEC Web of Conferences. Volume 170, 13 June 2018. International Science Conference on Business Technologies for Sustainable Urban Development, SPbWOSCE 2017. Paper number 01029

[12] Kankovskaya, A., Kalinina, O., \& Ilin, I. (2018). Economics of transport and sustainable development: Problems of high education in russia. Paper presented at the MATEC Web of Conferences, 239, Article number 08008

[13] Dubgorn, A., Zaychenko, I., Grashhenko, N. A rationale for choosing the mechanism of public-private partnership for the sustainable development of social infrastructure facilities. MATEC Web of Conferences. Volume 170, 13 June 2018, Number 010562017.

[14] Zaychenko, I., Borremans, A., \& Gutman, S. (2018). Analysis of administrative barriers in the industry of the high-rise construction in russian federation. Paper presented at the E3S Web of Conferences, , 33

[15] Jain, S., Kumar, N. V., Paventhan, A., Chinnaiyan, V. K., Arnachalam, V., \& Pradish, M. (2014). Survey on smart grid technologies- smart metering, IoT and EMS. 2014 IEEE Students' Conference on Electrical, Electronics and Computer Science. doi: $10.1109 /$ sceecs.2014.6804465

[16] Ilin, I., Levina, A., \& Iliashenko, O. (2018). Enterprise architecture analysis for energy efficiency of Saint-Petersburg underground. Advances in Intelligent Systems and Computing, 692, 1214-1223.

[17] Ilin, I., Shirokova, S., Lepekhin, A. IT Solution concept development for tracking and analyzing the labor effectiveness of employees (2018) E3S Web of Conferences, 33, № 03007. 